\title{
Relationship between upper and lower limbs muscle explosive strength with the vastus lateralis and biceps brachii architecture
}

\author{
Correlação entre a força muscular explosiva dos membros superiores e inferiores com a \\ arquitetura do vasto lateral e do bíceps braquial \\ Correlación entre la fuerza muscular explosiva de las extremidades superiores e inferiores \\ con la arquitectura del vasto lateral y el bíceps braquial
}

Conrado Laettª (D) , Ubiratã Gavilão ${ }^{a, b}$ (D), Jéssica do Rio (D) ${ }^{b}$, Victor Cossichª,b* (D), Carlos Gomes de Oliveira ${ }^{a}$

Keywords: Muscle architecture; Rate of torque development; Rate of force development; Explosive force.

\begin{abstract}
We aimed to assess upper and lower limbs explosive strength, and its correlation with biceps brachii (BB) and vastus lateralis (VL) architecture. Absolute and maximum torque normalized rate of torque development (RTD) were measured from isometric elbow flexion (EF) and knee extension (KE). BB and VL architectures were assessed by ultrasound. Absolute RTD of KE was higher (129-272\%), although normalized RTD was higher in EF (80-21\%). The absolute RTD was correlated to muscle thickness only in the BB $(r=.39-46)$. No relationship was found between muscle architecture and normalized RTD. In conclusion, the higher RTD from KE seems to be due to their greater strength. Only the muscle architecture could not explain the differences found in the RTD.
\end{abstract}

\section{RESUMO}

Nosso objetivo foi avaliar a força explosiva de membros superiores e inferiores e a sua correlação com a arquitetura do bíceps braquial (BB) e vasto lateral (VL). A taxa de desenvolvimento de torque (TDT) absoluta e normalizada pela força máxima foi medida na flexão de cotovelo (FC) e extensão de joelho (EJ). A arquitetura do BB e do VL foi avaliada por ultrassonografia. A TDT absoluta de EJ foi maior (129-272\%), mas a TDT normalizada foi maior na FC (80-21\%). A TDT absoluta foi correlacionada com a espessura do BB ( $r=.39-46)$. A TDT normalizada não foi correlacionada à arquitetura muscular. Concluindo, a TDT superior da EJ parece causada pela maior força máxima. Apenas a arquitetura muscular não parece explicar a diferença na TDT.

\section{RESUMEN}

Nuestro objetivo era evaluar la fuerza explosiva de los miembros superiores y inferiores y su correlación con la arquitectura del bíceps braquial (BB) y vasto lateral (VL). Se medio la tasa de desarrollo de torque (TDT) absoluta y normalizada por la fuerza máxima in la flexión de codo (FC) e extensión de rodilla (ER). La arquitectura del BB y VL fue evaluada por ultrasonido. La TDT absoluta de ER fue mayor (129-272\%), pero la TDT normalizada fue mayor en la FC (80-21\%). La TDT absoluta se correlacionó con el grosor del BB ( $r=.39-46)$. La TDT normalizada no se correlacionó con la arquitectura. En conclusión, la TDT superior del ER parece estar causado por la mayor fuerza máxima. La arquitectura muscular sola no parece explicar la diferencia en la TDT. 


\section{INTRODUCTION}

The human movement relies on muscle strength commonly assessed using the peak torque (PT), defined as the highest torque observed in an isokinetic test. However, real-life tasks demand force production in brief periods, thus the interest in explosive strength has been increasing (Buckthorpe and Roi, 2017; Maffiuletti et al., 2016). The explosive strength can be assessed by the rate of torque development (RTD), the slope of the torquetime curve at the very beginning of an explosive isometric maximal voluntary contraction (MVC) (Maffiuletti et al., 2016). The early RTD $(<100 \mathrm{~ms})$ is correlated to the muscle unit recruitment and their firing rate (Andersen and Aagaard, 2006; Del Vecchio et al., 2019), whilst the late RTD (>200ms) is closely related to the maximum force (Andersen and Aagaard, 2006; Folland et al., 2014), muscle thickness (Coratella et al., 2020; Stock et al., 2017), and muscle echography (Laett et al., 2021; Stock et al., 2017).

Several studies analyzed RTD of lower limbs (Stock et al., 2017; Del Vecchio et al., 2019), especially of the knee extension (KE) (Folland et al., 2014; Thompson et al., 2013). For instance, the KE RTD is shown to be correlated to the vertical jump ( $r=0.54$ to 0.60 ; Laett et al., 2021) and sprint performance ( $r=0.51$ to 0.61 ; Tillin et al., 2013). The upper limbs, however, had received considerably less attention (Follmer et al., 2017; Del Vecchio et al., 2018). The upper limbs are crucial to daily tasks, to sports performance, and commonly have their joints injured in throwing sports (Donaldson et al., 2020). Thus, the elbow flexion (EF) RTD may provide insights into the functional capacity and athletic performance, and can be a valuable tool for injury risk detection, as has been proposed for the KE (Buckthorpe and Roi, 2017).

Although studies have assessed the RTD in the upper (Follmer et al., 2017; Del Vecchio et al., 2018) and lower limbs (Laett et al., 2021; Stock et al., 2017) separately, we only found one study that assessed RTD of upper and lower limbs together (Ohtaka and Fujiwara, 2020). Ohtaka and Fujiwara (2020) found a higher absolute RTD for KE compared to EF during submaximal contractions. However, studies that observed the RTD to be related to functional or athletic performance have used maximum contractions (Laett et al., 2021; Thompson et al., 2013; Tillin et al., 2013). Furthermore, to compare the explosive force in muscle groups with different maximum strength, it is reasonable to analyze the relative explosive strength (Folland et al., 2014), which can be assessed by the RTD normalized by the maximum force (Maffiuletti et al., 2016).

The muscle architecture is defined as the fascicle arrangement and is a determinant of muscle force (Blazevich, 2006; Lieber and Fridén, 2000). The fascicle length (FL) dictates the muscle excursion and shortening velocity (Blazevich, 2006; Lieber and Fridén, 2000), whilst the fascicle angle (FA) and muscle thickness (MT) are classically related to the muscle maximum force
(Lieber and Fridén, 2000). The muscle architecture has been suggested to influence RTD (Blazevich et al., 2009; Coratella et al., 2020; Stock et al., 2017). It was shown that MT is correlated to RTD (Coratella et al., 2020; Stock et al., 2017), but the effects of FA and FL are still unclear (Blazevich et al., 2009; Coratella et al., 2020). Therefore, the present study aimed to analyze the RTD of $\mathrm{EF}$ and $\mathrm{KE}$, and also to analyze the correlation with biceps brachii (BB) and vastus lateralis (VL) muscle architecture, respectively.

\section{MATERIAL AND METHODS}

Thirty adults ( 17 males, 13 females, age: $30 \pm 7$ years old; body weight: $80.2 \pm 13.2 \mathrm{~kg}$; height: $173.2 \pm 8.6 \mathrm{~cm}$ ), physically active, classified according to the International Physical Activity Questionnaire - IPAQ (Craig et al., 2003), volunteered for this study. None of them had a history of neuromuscular disorders or orthopedic surgeries. The local ethical committee has approved this research and volunteers gave written informed consent.

\section{PROCEDURE}

Volunteers performed KE and EF MVCs in an isokinetic dynamometer (HUMAC NORM II, CSMI, USA) with the self-declared dominant limb (kick side test) to calculate the RTD. Isokinetic and isometric tests were sequentially performed for the same joint, whereas the $\mathrm{KE}$ and $\mathrm{EF}$ tests were randomly assigned. Ultrasound images of the $\mathrm{VL}$ and the BB were acquired with relaxed muscles before the isometric trials.

\section{DYNAMOMETRY}

For KE, the volunteers were seated upright with the hip at $85^{\circ}$. For $E F$, the volunteers laid supine with the shoulder at $45^{\circ}$ of abduction. The joints were aligned to the dynamometer rotation axis. The volunteers were familiarized by a warming-up procedure of 5 progressives (from $50 \%$ to maximum perceived effort) repetition at $30 \%$ s. After a minimum of 30 s of rest, volunteers performed an isokinetic test comprised of 5 maximal repetitions at $30^{\circ} \mathrm{s}$. The PT was defined as the highest torque measured, and the peak torque angle (PTA) was the joint angle in which the PT was achieved (Laett et al., 2021). After a minimum rest of 3 minutes, volunteers performed the isometric explosive MVC test at the PTA. Volunteers were instructed to exert force "as fast and hard as possible" without countermovement or pretension. One familiarization trial was performed before the MVC test. The volunteers performed three MVCs with minimum rest of 30s. The trial presenting the highest torque (MVC torque) was used for analyses. The torque signal was sampled at $100 \mathrm{~Hz}$.

\section{ULTRASONOGRAPHY}

Ultrasound images were obtained using a 7.5-MHz, 40-mm linear array probe (SDD900, ALOKA, Japan) 
in B-mode. An experienced researcher acquired the images with a lightweight foam fixation (Laett et al., 2021) to minimize the effects of pressure applied during measurements. The images of $V L$ were acquired in the middle distance between the major trochanter and the superior border of the patella (Stock et al., 2017), and those of BB were acquired in its distal portion, where the attachment sites of fascicles were visible (Asakawa et al., 2002).

\section{DATA ANALYSIS}

The torque signal was processed in Matlab 2014a (Mathworks Inc., USA) environment using in-house developed routines. The torque onset was set at three standard deviations from the baseline signal (Folland et al., 2014). After the onset determination, the signal was filtered using a $2^{\text {nd }}$ order low-pass Butterworth bidirectional filter ( $20 \mathrm{~Hz}$ cut-off frequency). RTD was calculated as the slope of the torque signal for the firsts 50, 100, 150, 200, and 250 ms (RTD50, RTD100, RTD150, RTD200, and RTD250, respectively) from the torque onset. All RTD values were expressed in absolute and normalized values by MVC torque. Previously, all those measures were tested for reliability $\left(\mathrm{ICC}_{2,1} \mathrm{MVC}\right.$ torque $=0.97$, RTD50=0.80, and RTD250=0.96).

For each muscle, we captured ultrasound images before each MVC. The variables were measured in each image, and their corresponding averages were computed. The VL MT is the average distance between the superficial and deep aponeurosis at the extremities and the middle of the image. The VL FA was measured three times as the angle between a fascicle and the deep aponeurosis and averaged. The VL FL was calculated as $\mathrm{MT} / \cos (\mathrm{FA})$ (Blazevich, 2006). As it is hard to identify the BB deep aponeurosis, the BB MT was taken as the maximum distance between the superficial and the distal internal aponeurosis (Hodges et al., 2003). The BB FA was measured three times as the angle between a fascicle and the distal internal aponeurosis (Asakawa et al., 2002). The same evaluator (Figure 1) used Image J 1.51 (National Institutes of Health, USA) for all measurements. Previously, all the ultrasound-derived measures were tested for reliability $\left(\mathrm{ICC}_{2,1} \mathrm{MT} \mathrm{VL}=0.82, \mathrm{BB}=0.92 ; \mathrm{FL}\right.$ $V L=0.58 ; F A V L=0.52, B B=0.54)$.

\section{STATISTICAL ANALYSIS}

The Shapiro-Wilk test checked the normality of variables. Two-way repeated-measures ANOVA (time from onset, joint) analyzed differences in RTD over time in both joints, with corresponding effect size $\left(\eta_{p}{ }^{2}\right)$. If sphericity could not be assumed, we applied the Greenhouse-Geisser correction. Further Bonferroni test was employed when applicable. The correlation was investigated by Pearson correlation coefficient and
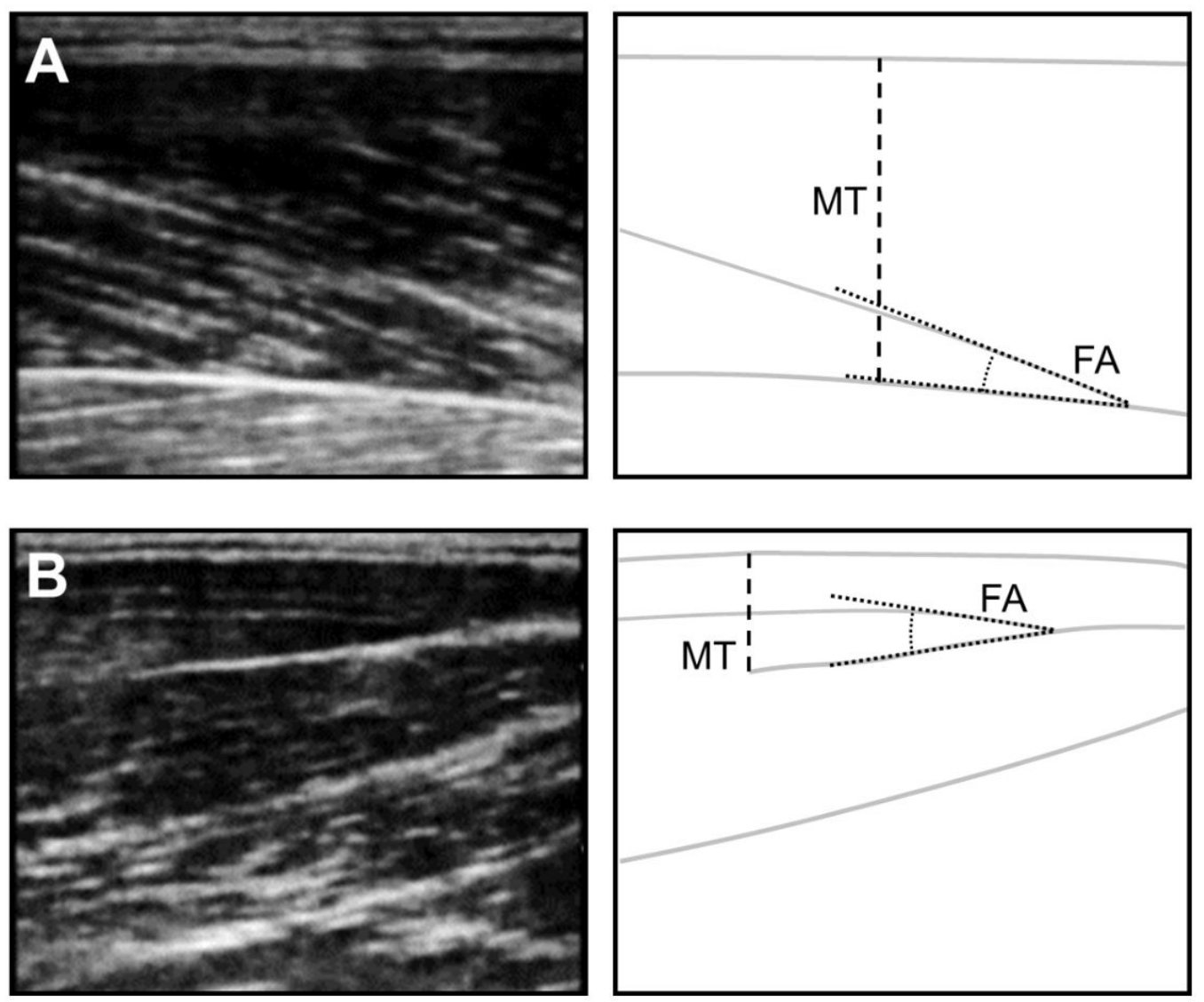

Figure 1. Left: Representative images of vastus lateralis (A) and biceps brachii (B) with a schematic drawing of aponeurosis and a fascicle. Right: An illustration of the muscle thickness (MT, dashed lines) and fascicle angle (FA, dotted lines) of each muscle. 
interpreted as described elsewhere (Schober et al., 2018). All statistical procedures were performed in SPSS 19 (IBM, USA) with the level of significance set to $\alpha=0.05$.

\section{RESULTS}

The KE PT and PTA was $213.2 \pm 61.9 \mathrm{Nm}, 69.5 \pm 9.2^{\circ}$, respectively, and EF PT and PTA was $57.1 \pm 17.7 \mathrm{Nm}$ and $81.3 \pm 19.0^{\circ}$. The MVC torques were $275.1 \pm 76.9 \mathrm{Nm}$ and $71.0 \pm 23.6 \mathrm{Nm}$ for $\mathrm{KE}$ and $\mathrm{EF}$, respectively. Significant effects of time from onset $\left(p<0.001, \eta_{p}{ }^{2}=0.90\right)$, joint $\left(p<0.001, \eta_{p}{ }^{2}=0.88\right)$, and interaction $\left(p<0.001, \eta_{p}{ }^{2}=0.80\right)$ was found on absolute RTD (Figure 2A). Pairwise comparisons showed a significantly higher RTD of KE when compared to the EF in all the time windows $(p<0.001$; Figure 2A). Significant effects of time from onset $\left(p<0.001, \eta_{p}{ }^{2}=0.91\right)$, joint $\left(p<0.001, \eta_{p}^{2}=0.30\right)$, and interaction ( $p=0.021, n_{p}{ }^{2}=0.35$ ) was found in normalized RTD (Figure 2B), and pairwise comparisons showed higher EF RTD than KE RTD in all the time windows $(p<0.001)$ except for $0-250 \mathrm{~ms}$ ( $p=0.21$; Figure $2 B$ ).

The MT and FA were $24.0 \pm 3.8 \mathrm{~mm}$ and $16.9 \pm 3.0^{\circ}$, respectively, in the $V L$ and $10.7 \pm 3.2 \mathrm{~mm}$ and $2.1 \pm 1.8^{\circ}$ in the BB. The VL FL was $83.8 \pm 14.7 \mathrm{~mm}$. The MT from both muscles showed moderate to strong positive correlations with PT and MVC torque (Table 1). The BB FA showed a weak correlation with RTD50 (Table 1). No significant correlation was found between normalized RTD and any architectural variables (Table 2).
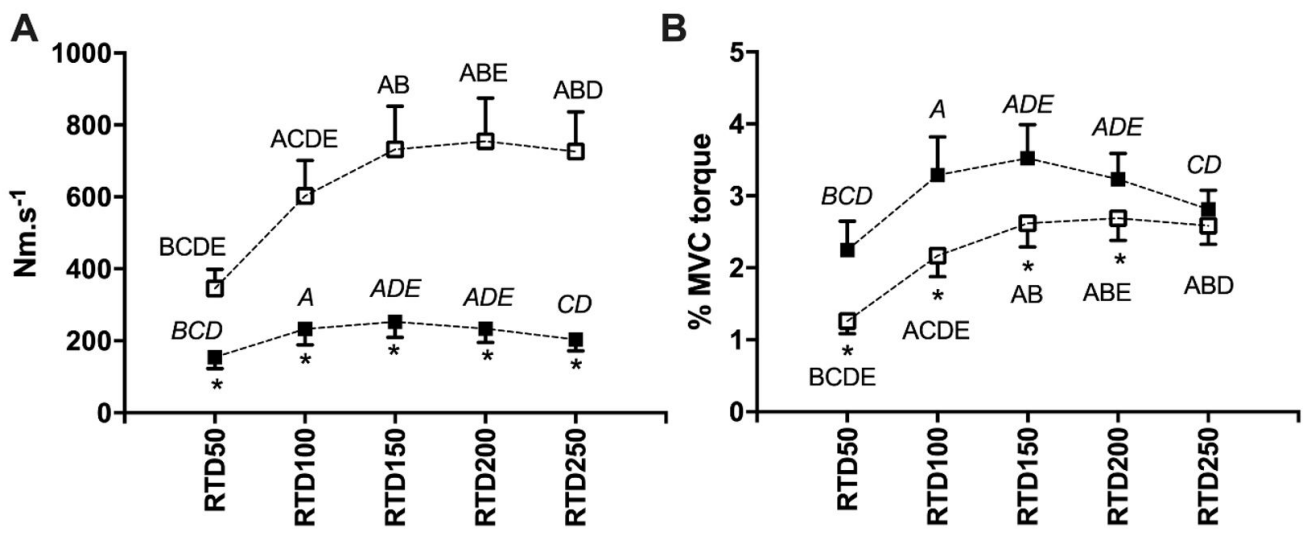

Figure 2. The absolute (A) and normalized (B) rate of torque development (RTD) of knee extension (open square) and elbow flexion (closed square). The letters indicate differences for the same joint (A, B, C, D, and E denotes difference from RTD50, RTD100, RTD150, RTD200, and RTD250, respectively $-p<0.001)$. differences between joints at the same time window $(p<0.001)$.

Table 1. Pearson correlation between architectural and torque variables.

\begin{tabular}{|c|c|c|c|c|c|c|c|}
\hline & PT & MVC torque & RTD50 & RTD100 & RTD150 & RTD200 & RTD250 \\
\hline \multicolumn{8}{|c|}{ Vastus Lateralis } \\
\hline MT & $0.44 *$ & $0.42 *$ & 0.16 & 0.15 & 0.17 & 0.19 & 0.21 \\
\hline FA & 0.17 & 0.22 & 0.00 & 0.01 & 0.02 & 0.03 & 0.03 \\
\hline $\mathrm{FL}$ & 0.29 & 0.18 & 0.18 & 0.15 & 0.14 & 0.15 & 0.17 \\
\hline \multicolumn{8}{|c|}{ Biceps brachii } \\
\hline MT & $0.63 *$ & $0.57 *$ & $0.44 *$ & $0.46 *$ & $0.44^{*}$ & $0.43^{*}$ & $0.44^{*}$ \\
\hline FA & 0.18 & 0.11 & $0.38 *$ & 0.27 & 0.15 & 0.08 & 0.05 \\
\hline
\end{tabular}

PT: peak torque; MVC: torque, maximal voluntary contraction torque; RTD: rate of torque development in which the numbers indicate the time from torque onset; MT: muscle thickness; FA: fascicle angle; FL: fascicle length. ${ }^{*}$-value $<0.05$.

Table 2. Pearson correlation between the architectural and normalized rate of torque development.

\begin{tabular}{lccccc}
\hline & Normalized RTD50 & Normalized RTD100 & NormalizedRTD150 & Normalized RTD200 & Normalized RTD250 \\
\hline MT & -0.20 & -0.19 & Vastus lateralis & -0.15 \\
FA & -0.16 & -0.14 & -0.17 & -0.16 & -0.15 \\
FL & 0.00 & -0.02 & -0.13 & -0.13 & 0.03 \\
\hline MT & -0.10 & -0.17 & -0.02 & 0.00 & -0.10 \\
FA & 0.17 & 0.16 & -0.17 & -0.14 \\
\hline
\end{tabular}

MT: muscle thickness; FA: fascicle angle; FL: fascicle length; RTD: rate of torque development in which the numbers indicate the time from torque onset. No significant correlations were found. 


\section{DISCUSSION}

This study aimed to analyze the RTD from KE and EF and the correlation among RTD with VL and BB muscle architecture. Due to the high correlation between absolute RTD and MVC torque reported (Andersen and Aagaard, 2006; Folland et al., 2014), normalized RTD (Maffiuletti et al., 2016) was also analyzed. This approach reduces the influence of maximal force upon the explosive strength, allowing comparison between different muscle groups (Maffiuletti et al., 2016; Del Vecchio et al., 2018).

As expected, the absolute RTD was greater in KE (129-272\%), which may be explained by the biggest quadriceps volume (Ward et al., 2009) and the higher MVC torque concerning the EF (208\%). Indeed, it was previously showed that VL MT, an estimator of the muscle volume (Franchi et al., 2018), is correlated to KE absolute RTD (Stock et al., 2017). Interestingly, the normalized RTD was higher in the first $200 \mathrm{~ms}$ of contraction in the EF (21-80\%), suggesting that when the effect of the maximum force on RTD is considered, the EF has superior performance. This difference can be due to distinct neural activation profiles, given that neural factors are shown to be crucial to early RTD of KE (Andersen and Aagaard, 2006; Folland et al., 2014) and EF (Del Vecchio et al., 2018). Other factors like fiber type distribution can also play a role (Methenitis et al., 2019) in such results, although previous reports do not indicate marked differences in the fiber type distribution between the VL and the BB (Methenitis et al., 2019; Pontén and Stål, 2007; Staron et al., 2000).

The only study that previously compared the upper and lower limbs RTD aimed to analyze the differences in force control during submaximal explosive contractions (Ohtaka and Fujiwara, 2020). The participants in the Ohtaka and Fujiwara (2020) study were instructed to exert KE and EF forces as accurately and fast as possible to match an isometric torque corresponding to 20,40 , and $60 \%$ of the previously measured MVC torque. The results showed higher accuracy in the lower limbs, and higher RTD in all intensities, which is similar to our findings. However, as previously discussed, the absolute RTD value may be improper to compare muscle groups with marked different sizes and maximum force. Also, while accessing explosive force it is usual to measure the RTD in an MVC (Coratella et al., 2020; Stock et al., 2017; Del Vecchio et al., 2019), and results from submaximal contraction may be difficult to interpret.

The muscle architecture of VL and BB may play a role in the observed difference in the RTD. The VL MT is an important contributor to the RTD, especially in the late RTD (Stock et al., 2017) and the BB MT showed a moderate positive correlation with absolute RTD. Therefore, the differences in the muscle thickness probably help to explain the differences found in the absolute RTD. However, with the current knowledge, it is not possible to infer if muscle architecture can explain the better performance of EF in the normalized RTD.

The VL and BB were chosen because they occupy about $40 \%$ of the knee extensors and elbow flexors volume, respectively (Ward et al., 2009) and largely contribute to the net torque (Blazevich et al., 2009; Murray et al., 2000; Stock et al., 2017). The MT was positively correlated to the maximum force in both muscles. This result suggests that, as expected, muscle size is related to the maximum force, as previously shown in the VL (Stock et al., 2017). The BB MT was also showed to influence the absolute RTD. The lack of correlation between VL MT and KE RTD can be in part explained because $V L$ is only one of the quadriceps muscles. Indeed, previous research showed that vastus intermedius (Coratella et al., 2020) and rectus femoris (Stock et al., 2017) explained part of the KE RTD variability. We also found a positive correlation between BB FA and early RTD. This should be interpreted with caution as the FA was shown to be correlated to the MT in pennate muscles (Kawakami et al., 2006) and it was suggested that thicker longitudinal muscles have steeper FA at the distal end (Gans, 1982). In this sense, the correlation found between FA and RTD could be an effect of the relationship between MT and RTD.

A limitation of the present study is that muscle activation, which affects the RTD (Folland et al., 2014; Del Vecchio et al., 2019), was not assessed. The use of supramaximal electrical stimulation (Andersen and Aagaard, 2006; Folland et al., 2014) or electromyography should be considered in the future. Also, the default dynamometer sampling rate of $100 \mathrm{~Hz}$ is lower than the previously suggested (Maffiuletti et al., 2016) and may underestimate RTD values and produce an aliasing effect on the acquired signal. Theoretically, a lower sample frequency could underestimate the early RTD. However, we consider that this was not a problem in our data, once any systematic error affected both $\mathrm{KE}$ and $\mathrm{EF}$, and thus did not affect statistical conclusions.

\section{CONCLUSION}

The higher explosive force from the KE seems to be due to the higher maximum force. Regardless of the joint, the muscle thickness was related to the maximum force. Despite the correlation between BB muscle thickness and absolute RTD, no correlation was found between architectural variables and relative explosive force. It suggests that other factors underly the differences in the relative explosive force between the analyzed upper and lower limb joints.

\section{FUNDING}

This study was financed in part by the Coordenação de Aperfeiçoamento de Pessoal de Nível Superior - Brasil (CAPES) - Finance Code 001. 


\section{CONFLICTS OF INTEREST}

The authors declare that there are no conflicts of interest.

\section{REFERENCES}

Andersen LL, Aagaard P. Influence of maximal muscle strength and intrinsic muscle contractile properties on contractile rate of force development. Eur J Appl Physiol. 2006;96(1):46-52. http://dx.doi.org/10.1007/s00421-0050070-z. PMid:16249918.

Asakawa DS, Pappas GP, Drace JE, Delp SL. Aponeurosis length and fascicle insertion angles of the biceps brachii. J Mech Med Biol. 2002;2(03n04):449-455. http://dx.doi. org/10.1142/S0219519402000484.

Blazevich AJ, Cannavan D, Horne S, Coleman DR, Aagaard P. Changes in muscle force-length properties affect the early rise of force in vivo. Muscle Nerve. 2009;39(4):512-20. http://dx.doi.org/10.1002/mus.21259. PMid:19296490.

Blazevich AJ. Effects of physical training and detraining, immobilisation, growth and aging on human fascicle geometry. Sports Med. 2006;36(12):1003-17. http:// dx.doi.org/10.2165/00007256-200636120-00002. PMid:17123325.

Buckthorpe M, Roi GS. The time has come to incorporate a greater focus on rate of force development training in the sports injury rehabilitation process. Muscles Ligaments Tendons J. 2017;7(3):435-41. http://dx.doi.org/10.11138/ $\mathrm{mltj} / 2017.7 .3 .435$. PMid:29387636.

Coratella G, Longo S, Borrelli M, Doria C, Cè E, Esposito F. Vastus intermedius muscle architecture predicts the late phase of the knee extension rate of force development in recreationally resistance-trained men. J Sci Med Sport. 2020;23(11):1100-4. http://dx.doi.org/10.1016/j. jsams.2020.04.006. PMid:32416973.

Craig CL, Marshall AL, Sj??Str??M M, Bauman A, Booth $\mathrm{ML}$, Ainsworth $\mathrm{B}$, et al. International physical activity questionnaire: 12-Country reliability and validity. Med Sci Sports Exerc. 2003;35(8):1381-95. http:// dx.doi.org/10.1249/01.MSS.0000078924.61453.FB. PMid:12900694.

Del Vecchio A, Negro F, Falla D, Bazzucchi I, Farina D, Felici F. Higher muscle fiber conduction velocity and early rate of torque development in chronically strengthtrained individuals. J Appl Physiol. 2018;125(4):1218-26. http://dx.doi.org/10.1152/japplphysiol.00025.2018. PMid:30024336.

Del Vecchio A, Negro F, Holobar A, Casolo A, Folland JP, Felici $F$, et al. You are as fast as your motor neurons: speed of recruitment and maximal discharge of motor neurons determine the maximal rate of force development in humans. J Physiol. 2019;597(9):2445-56. http://dx.doi. org/10.1113/JP277396. PMid:30768687.

Donaldson MJ, McCurdy KW, Thomas SJ, Myers NL. Does humeral torsion play a role in shoulder and elbow injury profiles of overhead athletes: a systematic review. J Shoulder Elbow Surg. 2020;29(8):1712-25. http://dx.doi. org/10.1016/j.jse.2020.01.080. PMid:32327268.
Folland JP, Buckthorpe MW, Hannah R. Human capacity for explosive force production: neural and contractile determinants. Scand J Med Sci Sports. 2014;24(6):894-906. http://dx.doi.org/10.1111/sms.12131. PMid:25754620.

Follmer B, Dellagrana RA, de Lima LAP, Herzog W, Diefenthaeler F. Analysis of elbow muscle strength parameters in Brazilian jiu-jitsu practitioners. J Sports Sci. 2017;35(23):2373-9. http://dx.doi.org/10.1080/02640414.2016.1267388. PMid:27976985.

Franchi MV, Longo S, Mallinson J, Quinlan JI, Taylor T, Greenhaff PL, et al. Muscle thickness correlates to muscle cross-sectional area in the assessment of strength training-induced hypertrophy. Scand J Med Sci Sports. 2018;28(3):846-53. http://dx.doi.org/10.1111/sms.12961. PMid:28805932.

Gans C. Fiber architecture and muscle function. ExercSportSci Rev. 1982;10:160-207. http://dx.doi.org/10.1249/00003677198201000-00006. PMid:6749514.

Hodges PW, Pengel LHM, Herbert RD, Gandevia SC. Measurement of muscle contraction with ultrasound imaging. Muscle Nerve. 2003;27(6):682-92. http://dx.doi. org/10.1002/mus.10375. PMid:12766979.

Kawakami Y, Abe T, Kanehisa H, Fukunaga T. Human skeletal muscle size and architecture: variability and interdependence. Am J Hum Biol. 2006;18(6):845-8. http:// dx.doi.org/10.1002/ajhb.20561. PMid:17039483.

Laett CT, Cossich V, Goes RA, Gavilão U, Rites A, Oliveira CG. Relationship between vastus lateralis muscle ultrasound echography, knee extensors rate of torque development, and jump height in professional soccer athletes. Sport Sci Health. 2021;17(2):299-306. http://dx.doi.org/10.1007/ s11332-020-00681-z.

Lieber RL, Fridén J. unctional and clinical significance of skeletal muscle architecture. Muscle Nerve. 2000;23(11):1647-66. http://dx.doi.org/10.1002/10974598(200011)23:11<1647::AID-MUS1>3.0.CO;2-M. PMid:11054744.

Maffiuletti NA, Aagaard P, Blazevich AJ, Folland J, Tillin N, Duchateau J. Rate of force development: physiological and methodological considerations. Eur J Appl Physiol. 2016;116(6):1091-116. http://dx.doi.org/10.1007/s00421016-3346-6. PMid:26941023.

Methenitis S, Spengos K, Zaras N, Stasinaki AN, Papadimas G, Karampatsos G, et al. Fiber Type Composition and Rate of Force Development in Endurance- and Resistance-Trained Individuals. J Strength Cond Res. 2019;33(9):2388-97. http://dx.doi.org/10.1519/JSC.0000000000002150. PMid:28737590.

Murray WM, Buchanan TS, Delp SL. The isometric functional capacity of muscles that cross the elbow. J Biomech. 2000;33(8):943-52. http://dx.doi.org/10.1016/S00219290(00)00051-8. PMid:10828324.

Ohtaka C, Fujiwara M. Force control characteristics for generation and relaxation compared between the upper and lower limbs. J Hum Sport Exerc. 2020. In press.

Pontén EM, Stål PS. Decreased capillarization and a shift to fast myosin heavy chain (IIx) in the biceps brachii muscle from young adults with spastic paresis. J Neurol Sci. 2007;253(1- 
2):25-33. http://dx.doi.org/10.1016/j.jns.2006.11.006. PMid:17196619.

Schober P, Boer C, Schwarte LA. Correlation coefficients: Appropriate use and interpretation. Anesth Analg. 2018;126(5):1763-8. http://dx.doi.org/10.1213/ ANE.0000000000002864. PMid:29481436.

Staron RS, Hagerman FC, Hikida RS, Murray TF, Hostler $D P$, Crill MT, et al. Fiber type composition of the vastus lateralis muscle of young men and women. J Histochem Cytochem. 2000;48(5):623-9. http://dx.doi. org/10.1177/002215540004800506. PMid:10769046.

Stock MS, Mota JA, Hernandez JM, Thompson BJ. Echo intensity and muscle thickness as predictors \{Of\} athleticism and isometric strength in middle-school boys. Muscle Nerve. 2017;55(5):685-92. http://dx.doi.org/10.1002/mus.25395. PMid:27592862.
Thompson BJ, Ryan ED, Sobolewski EJ, Smith DB, Conchola EC, Akehi K, et al. Can maximal and rapid isometric torque characteristics predict playing level in division i american collegiate football players? J Strength Cond Res. 2013;27(3):655-61. http://dx.doi.org/10.1519/ JSC.0b013e31825bb56c. PMid:22592169.

Tillin NA, Pain MTG, Folland J. Explosive force production during isometric squats correlates with athletic performance in rugby union players. J Sports Sci. 2013;31(1):66-76. http://dx.doi.org/10.1080/02640414.2012.720704. PMid:22938509.

Ward SR, Eng CM, Smallwood LH, Lieber RL. Are current measurements of lower extremity muscle architecture accurate? Clin Orthop Relat Res. 2009;467(4):107482. http://dx.doi.org/10.1007/s11999-008-0594-8. PMid:18972175. 